\title{
Choose the Best Coach
}

YU Dongli

North China Electric Power University（Baoding）， Baoding 071000， China team results.

\begin{abstract}
In our thesis, the goal is to rank college coaches in such sports as college hockey or field hockey, football, baseball or softball, basketball, or soccer and then choose the best college coach or coaches for the previous century.
\end{abstract}

Key words: the best; coach; model design

\section{Introduction}

Who is the best college coach ever? Many people are eager to know the answer. In order to solve the problem above and provide an efficient strategy for the rank of the college coach, we use three models in our paper.

In first model, we established an evaluation system for college coaches' comprehensive capacity. It contains four level-one targets and ten level-two targets. By using AHP, we analyze weight of each target above. In our second model, based on Grey System Theory and Fuzzy Theory, we get coaches' different index scores at different times. Then, according to the fuzzy evaluation matrix and evaluation result, we calculate the coach's comprehensive ability level.

By using the method above, we can give a score to each college coach's comprehensive capacity. By comparing different coaches' score, we can finally choose the best college coach in the last century. The higher the score, the better the coach. Eventually, Joe Paterno was identified as the best college football coach in the last century. Mike Krzyzewski was identified as the best college basketball coach. And Gordie Gillespie was the best college baseball coach in the last century.

When it comes to the impact of time line horizon, we assume that the level of a coach is reflected only by win-loss pct of team the coach lead. In the third model, by using the method of linear regression, we find $\mathrm{b}$ and $\mathrm{R}^{2}$ are nearly equal to zero, so we get the result that time has little impact on the level of a coach, but there are fluctuations in the balance of a coach's level.

As for different gender, the evaluation index has not changed, so we think gender doesn't make a difference in this problem. For different sports, the weight of each index is different. We can also choose the best coaches of different sports by using the model above. All we need to do is analyze and change the weight of each index in different sports.

\section{2 . Introduction}

In recent years, college students' sports events caused a widespread concern in society, college athletics gradually became an important component of world's athletics. High-level college sports teams coaches as one of the most important components, their professional qualities, training levels and comprehensive management capacities will greatly affect the sports training, management, and sports

Sports Illustrated, a magazine for sports enthusiasts, is looking for the "best all time college coach" male or female for the previous century. Actually, who is the best college coach ever is a question many people eager to know. Therefore the establishment of a set of objective and rational evaluation system which can reflect the true comprehensive capacity of high-level college sports teams' coaches is very important.

\section{Problem Analysis}

According to related literature, we found the ability a coach needs is very complex. It includes four aspects: record, experience, ability and self-cultivation. Record includes win-loss pct and awards. Experience includes years of coach and games played. Ability includes selection ability, management, innovative and command ability. Self-cultivation includes education and morality.

However, it is difficult to simply describe and measure them with qualitative or quantitative method. Especially in such a complex and multi-level management system which consists of schools, coaches, athletes and multiple factors. Obviously, it is impossible to achieve satisfactory result with traditional methods. So, it is crucial to establish a new and high-level comprehensive ability-ranking system.

Method used: document literature, questionnaire, expert evaluation, mathematical statistics ( including AHP, Fuzzy comprehensive evaluation method, Grey relational analysis method )

\section{Assumptions}

The development of the mathematical model requires several assumptions. The following are our assumptions:

- Self-ability of coaches are evaluated only by self-factor, ignore the external environmental factors.

- Male or female coaches are evaluated in the same standard.

- Do not consider the physical condition of coaches.

- When we analyze coaches' capacity in different time line horizon, we assume the level of a coach is reflected only by win-lost pct of teams the coach lead.

\section{5 . Model Design}

\subsection{Determine the weight-—AHP}

We synthesize the research of relative importance of evaluation criteria and evaluation factors. By using AHP, build up comparison judgment weight matrix for index system.

First, we assume $\mathbf{U}$ index group and build up hierarchy 
structure model. The primary index and the secondary index $\quad$ are described clearly in Figure 1.

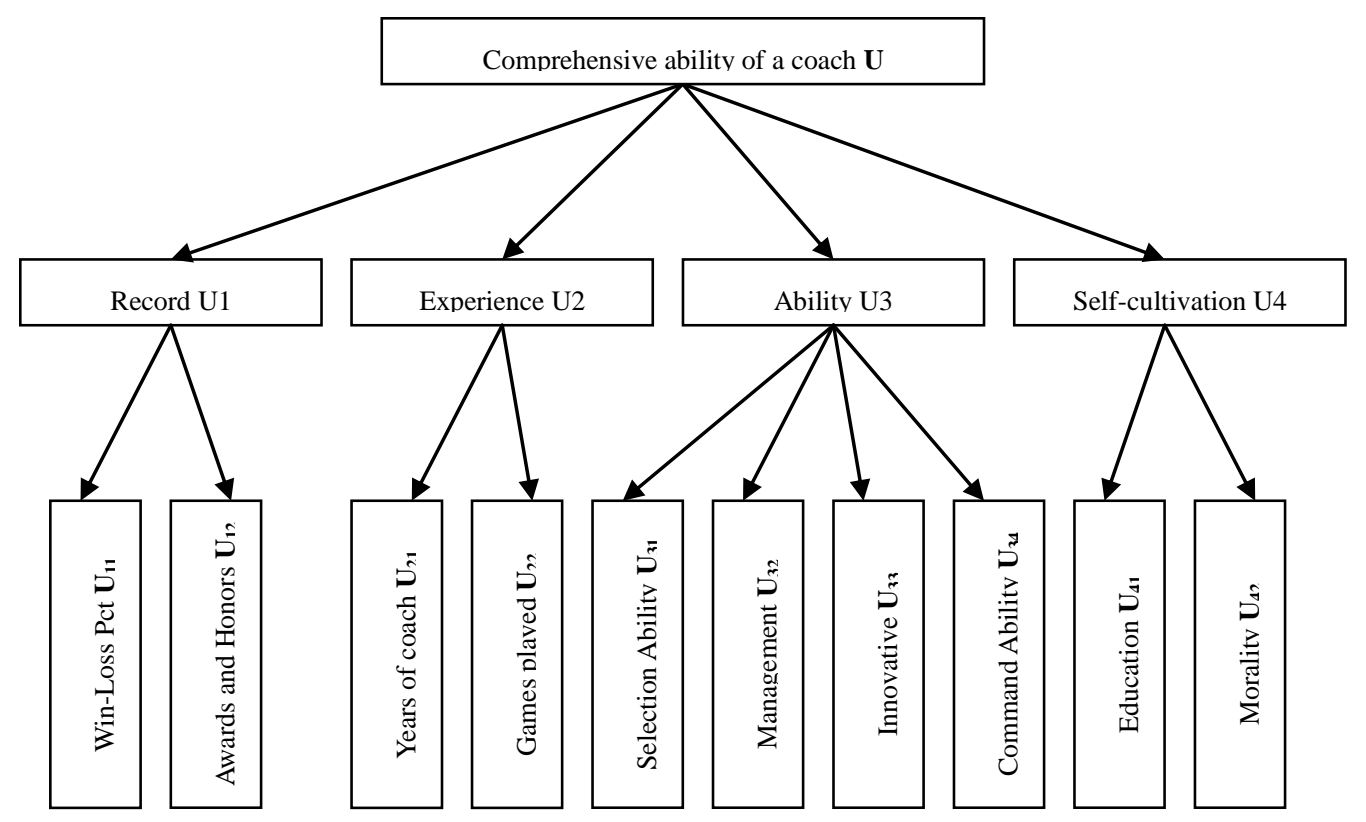

Figure 1 the primary index and the secondary index are described clearly

Second, build up judgment matrix for four primary indexes.

\begin{tabular}{c|cccc}
$\mathrm{U}$ & $\mathrm{U}_{1}$ & $\mathrm{U}_{2}$ & $\mathrm{U}_{3}$ & $\mathrm{U}_{4}$ \\
\hline $\mathrm{U}_{1}$ & 1 & 6 & 4 & 7 \\
$\mathrm{U}_{2}$ & $1 / 6$ & 1 & $1 / 3$ & 2 \\
$\mathrm{U}_{3}$ & $1 / 4$ & 3 & 1 & 5 \\
$\mathrm{U}_{4}$ & $1 / 7$ & $1 / 2$ & $1 / 5$ & 1
\end{tabular}

Maximal eigenvalue $\lambda \max =4.1211$, and we get consensus index $\boldsymbol{C} \boldsymbol{I}=\frac{\lambda_{\max }-4}{4-1}=0.0404$. To examine if judgment matrix has a satisfactory consistency, it is necessary to compare CI and consensus index RI (Table 1). RI of 4×4matrix is 0.90 , so $\mathbf{C R}=\frac{C I}{R I}=\frac{0.0404}{0.90}=0.044989$, so judgment matrix has a satisfactory consistency.

\begin{tabular}{cccccc}
\multicolumn{5}{c}{ Table 1 judgment matrix for four primary indexes. } \\
\hline$n$ & 1 & 2 & 3 & 4 & 5 \\
\hline$R I$ & 0 & 0 & 0.58 & 0.90 & 1.12 \\
\hline$n$ & 6 & 7 & 8 & 9 \\
\hline$R I$ & 1.24 & 1.32 & 1.41 & 1.45 \\
\hline
\end{tabular}


Table 2 evaluation sample matrix and set coaches' level

\begin{tabular}{ccccccccccc}
\hline & $\mathrm{U}_{11}$ & $\mathrm{U}_{12}$ & $\mathrm{U}_{21}$ & $\mathrm{U}_{22}$ & $\mathrm{U}_{31}$ & $\mathrm{U}_{32}$ & $\mathrm{U}_{33}$ & $\mathrm{U}_{34}$ & $\mathrm{U}_{41}$ & $\mathrm{U}_{42}$ \\
\hline Time 1 & 7 & 5 & 6 & 6 & 6 & 6 & 4 & 6 & 8 & 7 \\
Time 2 & 8 & 7 & 7 & 7 & 7 & 7 & 6 & 7 & 8 & 7 \\
Time 3 & 7 & 5 & 8 & 8 & 8 & 7 & 8 & 8 & 8 & 7 \\
Time 4 & 10 & 8 & 9 & 9 & 9 & 8 & 7 & 9 & 8 & 8 \\
Time 5 & 6 & 10 & 10 & 10 & 8 & 6 & 6 & 8 & 8 & 8 \\
\hline
\end{tabular}

Grade coaches' level into level I(8 10), ,II(7 8) ,III(6 7), IV $(0 \sim 6)$.

$$
\mathrm{V}=\{8,7,6,5\}
$$

5.2.2 Determine evaluation grey classification

Determining evaluation grey classification needs determine the level and value of grey classification and the definite weighted function of the value.

Build up four definite weighted functions:

1) $\otimes_{1} \in\left[\mathrm{d}_{\mathrm{ij},}, \infty\right):$

$$
\mathrm{f}_{1}\left(\mathrm{~d}_{\mathrm{ij}}\right)\left\{\begin{array}{cc}
d_{i j} / 8 & d i j \in[0,8] \\
1 & d i j \in(8,+\infty) \\
0 & d i j \in(-\infty, 0)
\end{array}\right.
$$

2) $\otimes_{2} \in[0,7,14]:$

$$
\mathrm{f}_{2}\left(\mathrm{~d}_{\mathrm{ij}}\right)\left\{\begin{array}{cc}
d_{i j} / 7 & d_{i j} \in[0,7] \\
2-d_{i j} / 7 & d_{i j} \in(7,14] \\
0 & d_{i j} \notin[0,14]
\end{array}\right.
$$

3) $\otimes_{3} \in[0,6,12]$ :

$$
\mathrm{f}_{3}\left(\mathrm{~d}_{\mathrm{ij}}\right)\left\{\begin{array}{cc}
d_{i j} / 6 & d_{i j} \in[0,6] \\
2-d_{i j} / 6 & d_{i j} \in(6,12] \\
0 & d_{i j} \notin[0,12]
\end{array}\right.
$$

4) $\otimes_{4} \in[0,5,10]:$

$$
\mathrm{f}_{4}\left(\mathrm{~d}_{\mathrm{ij}}\right)\left\{\begin{array}{cc}
1 & d_{i j} \in[0,5] \\
2-d_{i j} / 5 & d_{i j} \in(5,10] \\
0 & d_{i j} \notin(10,+\infty)
\end{array}\right.
$$

5.2.3 Calculate grey statistics and weight matrix

Calculate $\boldsymbol{n}_{\mathbf{i j}}, \boldsymbol{n}_{\mathbf{i}}$ and $\boldsymbol{r}_{\mathrm{ij}}(\mathrm{i}=1,2,3 \ldots 20, \mathrm{j}=1,2,3,4)$, then we can get weight matrix R:

Index $\mathbf{U}_{1}$ for $\otimes_{3}$ ' grey statistics:

$n_{11}=f_{1}\left(\mathbf{d}_{11}\right)+f_{1}\left(\mathbf{d}_{21}\right)+f_{1}\left(\mathbf{d}_{31}\right)+f_{1}\left(\mathbf{d}_{41}\right)+f_{1}\left(\mathbf{d}_{51}\right)$ $=f_{1}(7)+f_{1}(8)+f 1(7)+f 1(10)+f 1(6)$
Similarly:

$=4.500$;

$$
\begin{aligned}
& n_{12}=4.2857 ; \\
& n_{13}=3.6667 ; \\
& n_{14}=2.4000 ; \\
& n_{1}=n_{11}+n_{12}+n_{13}+n_{14}=14.8524 ;
\end{aligned}
$$

Calculate weight matrix $\boldsymbol{r}_{\mathrm{ij}}: \boldsymbol{r}_{\mathrm{ij}}=\boldsymbol{n}_{\mathrm{ij}} / \boldsymbol{n}_{\mathrm{i}}$ :

$\boldsymbol{r}_{11}=\boldsymbol{n}_{11} / \boldsymbol{n}_{1}=0.3030, \quad \boldsymbol{r}_{13}=\boldsymbol{n}_{13} / \boldsymbol{n}_{1}=0.2886, \quad \boldsymbol{r}_{13}=\boldsymbol{n}_{13} / \boldsymbol{n}_{1}=0.2469$, $\boldsymbol{r}_{14}=0.1616 \ldots \ldots$.

Then we get weight matrix R:

$$
R=\left[\begin{array}{llll}
0.3030 & 0.2886 & 0.2469 & 0.1616 \\
0.2848 & 0.2663 & 0.2417 & 0.2072 \\
0.1180 & 0.1348 & 0.1573 & 0.5899 \\
0.3313 & 0.2866 & 0.2388 & 0.1432 \\
0.3313 & 0.2866 & 0.2388 & 0.1432 \\
0.2599 & 0.2795 & 0.2650 & 0.1957 \\
0.2455 & 0.2625 & 0.2640 & 0.2281 \\
0.3088 & 0.2861 & 0.2448 & 0.1602 \\
0.3420 & 0.2932 & 0.2280 & 0.1368 \\
0.2932 & 0.2989 & 0.2430 & 0.1648
\end{array}\right]
$$

5.2.4 Calculate the fuzzy evaluation matrix and evaluation result

Fuzzy evaluation matrix:

Evaluation result:

$$
\boldsymbol{B}=\boldsymbol{W} \boldsymbol{R}=\{0.2892,0.2750,0.2419,0.1939\} ;
$$

$\boldsymbol{Z}=\boldsymbol{B} \boldsymbol{V}=6.6595$

So, this coach' comprehensive ability level is level III.

\subsection{The impact of time line horizon --- linear regression}

The capacity of a coach is affected by various factors, such as physical quality of players and performance on sport. Time is also an important factor which affect the level of a coach. In the last model, we just 
get the average level of a coach in different time duration, we did not explain the change of coaches' capacity as time goes by. Next we explain the impact of time.

The win-lost percentage of the team a coach lead is a factor that can reflect coaches' capacity best of all. When

we analyze coach' capacity in different time line horizon, we firstly assume the level of a coach is reflected only by win-lost pct of teams the coach lead. As for Steve Spurrier, a college football coach, the win-lost pct of teams he led from 1987 to 2013 are listed in Table 3.

Table 3 a college football coach, the win-lost pct of teams he led from 1987 to 2013 are listed

\begin{tabular}{ccccccccc}
\hline Year & 1987 & 1988 & 1989 & 1990 & 1991 & 1992 & 1993 & 1994 \\
\hline Win-Lost Pct & 0.455 & 0.682 & 0.667 & 0.818 & 0.833 & 0.692 & 0.846 & 0.808 \\
\hline Year & 1995 & 1996 & 1997 & 1998 & 1999 & 2000 & 2001 & 2005 \\
\hline Win-Lost Pct & 0.923 & 0.923 & 0.833 & 0.833 & 0.692 & 0.769 & 0.833 & 0.538 \\
\hline Year & 2006 & 2007 & 2008 & 2009 & 2010 & 2011 & 2012 & 2013 \\
\hline Win-Lost Pct & 0.615 & 0.500 & 0.538 & 0.538 & 0.643 & 0.846 & 0.846 & 0.846 \\
\hline
\end{tabular}

Assume win-lost pct of his team is $X_{t}, t=y e a r-1980$, then $\mathrm{t} \in(0,40)$

$$
\mathrm{X}_{\mathrm{t}}=\mathrm{a}+\mathrm{bt}+\varepsilon_{\mathrm{t}},(\mathrm{a}, \mathrm{b} \text { is constant })
$$

$\varepsilon_{\mathrm{t}} \sim \mathrm{N}(0,1)$, then

use function

$$
\mathrm{E}\left(\mathrm{X}_{\mathrm{t}}\right)=\mathrm{a}+\mathrm{bt}
$$

$$
\mathrm{F}(\mathrm{a}, \mathrm{b})=\sum_{i=1}^{n}\left[y_{i}-\left(a+b t_{i}\right)\right]^{2}
$$

measure goodness-of-fit of regression line. make $\partial F / \partial a$ and $\partial F / \partial b$ zero, we get:

$$
\begin{gathered}
\sum_{i=1}^{n} y_{i}=\mathrm{na}+\mathrm{b} \sum_{i=1}^{n} t_{i} \\
\sum_{i=1}^{n} t_{i} y_{i}=\mathrm{a} \sum_{i=1}^{n} t_{i}+\mathrm{b} \sum_{i=1}^{n} t_{i}^{2}
\end{gathered}
$$

the result:

$$
a=0.771 \quad b=0.0021
$$

and

$$
R^{2}=\frac{\sum_{i=1}^{n}\left(\widehat{y}_{i}-\bar{y}\right)^{2}}{\sum_{i=1}^{n}\left(y_{i}-\bar{y}\right)^{2}}=0.1656
$$

Conclusion:

1) $b$ is nearly equal to 0 , then time has little impact on the level of coach;

2) $R^{2}$ is nearly equal to 0 , it reflects there are fluctuations in the balance of coaches' level. This phenomenon may caused by inherent or environmental factors.

3) Other coaches' level is also accordance with above conclusion.

According to conclusion above, time has little impact on the level of a coach. With time passing, the games' role changing and people's physical quality improving, the evaluation judgment of a coach may be influenced. Other factors such as people's awareness and social condition also impact. So there are fluctuations in coaches' level in a short time. However, coaches are generally very adaptable, they could go back to the normal level after brief fluctuation . Therefore, time has little impact on the level of coaches but there are fluctuations in the balance of coaches' level.

\section{6 . Conclusion}

This paper uses three models to solve the problem that choose the best college in the previous century. At the same time we also discuss the impact of time on the evaluation to coaches.

First, we summarize four primary indexes and ten secondary indexes that influence the evaluation of coaches. For the purpose of determine the weight of each index, we build up model based on Analytic Hierarchy Process. Next, we build up judgment matrix for four primary indexes and we conclude that judgment matrix has a satisfactory consistency under the help of MATLAB 7.0. Finally, by using AHP, we calculate the weight of each index and get the weight group.

The model 2 is based on Grey System Theory and Fuzzy Theory, using the result of model 1. Through grading each index of every coach, we calculate the fuzzy evaluation matrix and get comprehensive ability level of each coach. Finally, we choose top 5 coaches in each of 3 different sports.

The model 3 is for discuss the impact of time to a coach's evaluation, using the knowledge of linear regression. When we analyze coaches' capacity in different time line horizon, we firstly assume the level of a coach is reflected only by win-lost pct of teams the coach lead. Finally we find $\mathrm{b}$ and $\mathrm{R}^{2}$ are nearly equal to zero, so we get the result that time has little impact on the level of a coach but there are fluctuations in the balance of a coach's level. 


\section{Strengths}

\section{Strengths and Weaknesses}

- Model 1 is based on quantitative analysis, so our results of evaluation are objective and efficient.

- In model 2 we use different methods to grade coaches' level more effectively.

- Our model can be used to solve other similar questions in the different area.

Paper for Sports Illustrated

To whom it may concern:

\section{Weaknesses}

- In model 1 , our evaluation is restricted by limited data.

- In model 3, we define several restrictions to simplify calculation process, which is against our goal to access the optimal result.

- In model 3, there are fluctuations in the balance of a coach's level due to the external environmental factors.

Top 5 coaches

sports.

Eventually, Joe Paterno was identified as the best

\begin{tabular}{cccccc}
\hline \multicolumn{2}{c}{ Basketball } & \multicolumn{2}{c}{ Football } & \multicolumn{2}{c}{ Baseball } \\
Coach & Final Rank & Coach & Final Rank & Coach & Final Rank \\
\hline Mike Krzyzewski & 1 & Joe Paterno & 1 & Gordie Gillespie & 1 \\
John Wooden & 2 & Amos Alonzo & 2 & Don Schaly & 2 \\
Adolph Rupp & 3 & Bobby Bowden & 3 & Augie Garrido & 3 \\
Lute 0lson & 4 & Pop Warner & 4 & Cliff Gustafson & 4 \\
Bob Huggins & 5 & Phillip Fulmer & 5 & Jim Morris & 5 \\
\hline
\end{tabular}

Nowadays, college students' sports events caused widespread concern in society. Obviously, college coaches plays an important role. A college coach's capacity always determines the result of games. So who is the "best all time college coach"? Many sports fans are eager to know the answer. Here we would like to give a brief introduction that how we selected the best college coach for the previous century.

In order to choose the best college coach, first, we need to know what characteristics a college coach needs to have. That is to say, what factors will affect the selection of the best coach. External environmental factor is one part, such as capital investment, related policies etc. But a college coach's comprehensive capacity is the key point. To simplify the problem, we just ignore the external environmental factors. According to the related data, we evaluate coaches from four aspects: record, experience, self-ability and self-cultivation. Then we divided the above four aspects into ten small parts. Record includes win-loss pct and awards. Experience includes years of coaching and games played. Ability includes selection ability, management, innovative and command ability. Self-cultivation includes education and morality.

Based on the data we collected, we graded each index (the range of the score is $1 \sim 10$ ). Next, according to the college coach's capacity evaluation standard and our experience in daily life, we ranked these ten indexes according to the importance to the evaluation of a college coach, we calculated the proportion of each index, then grade coaches according to the score of each index and the proportion it has.

The higher the score, the better the coach. Since gender of a coach has little effect on the sport teams and physical condition of a player has little change over a period of time, we neglect the influence of the gender and other irrelative factors. Finally we get top 5 coaches in each of 3 different college football coach in the last century. Mike Krzyzewski was identified as the best college basketball coach. And Gordie Gillespie was the best college baseball coach in the last century.

Furthermore, because the evaluation of college coaches is based on four factors: record, experience, self-ability and self-cultivation, this model can be applied to every sport such as college hockey, football or baseball.

Yours sincerely.

References
[1]College football coach Index
http://www.sports-reference.com/cfb/coaches/

[2]College Basketball coach Index

http://www.sports-reference.com/cbb/coaches/

[3]NCAA-Men's Basketball

http://espn.go.com/mens-college-basketball/

[4]Top Ten College Baseball Coaches Ever

http://www.mademan.com/mm/10-best-college-baseball-co aches-ever.html

[5]Top Ten College Football Coaches of All-Time

http://www.barrystickets.com/blog/top-ten-college-footballcoaches-of-all-time/

[6]The Best College Football Coaches of All Time.

http://www.ranker.com/list/best-college-football-coaches-of -all-time-/johnwarner

[7]Search for NCAA coach.

http://web1.ncaa.org/stats/StatsSrv/careersearch

[8]NCAA:http://www.ncaa.com/

[9]Wikipedia:https://www.wikipedia.org/ 